\title{
Open Media Science
}

\begin{abstract}
In this article, we present three challenges to the emerging Open Science (OS) movement: the challenge of communication, collaboration and cultivation of scientific research. We argue that to address these challenges OS needs to include other forms of data than what can be captured in a text and extend into a fully-fledged Open Media movement engaging with new media and non-traditional formats of science communication. We discuss two cases where experiments with open media have driven new collaborations between scientists and documentarists. We use the cases to illustrate different advantages of using open media to face the challenges of OS.
\end{abstract}

Keywords

Context: the what, why and how of Open Science
Public engagement with science and technology; Science communication: theory and models; Visual communication
Open Science (OS) is rapidly emerging as a new scientific movement and practice [David, 2004; Molloy, 2011; Allen, 2011; Redfield, 2012; EC, 2014;

Geoghegan-Quinn, 2014]. Openness in this context is understood as "opening up" the research process as early as is practically possible [Nielsen, 2011]. Here the notion of 'open' functions as an umbrella term for opening up the different dimensions by which research is processed, validated and circulated: 1) methods (Open Methodology), 2) software (Open Source), 3) datasets (Open Data), 4) peer reviewing (Open Peer Review), 5) publications (Open Access) and 6) teaching (Open Educational Resources) [Watson, 2015; see also OpenScience ASAP; Kraker et al., 2011]. These different dimensions of openness share a commitment to opening up science to free access, collective use, mutual modification and knowledge sharing for any purpose which preserves the provenance and transparency of science.

\subsection{A strong program}

While there is currently no generally accepted definition of OS, many supporters of the movement [e.g. Molloy, 2011; Watson, 2015] adopt a strong program: Open Science simply means better science. Recurrent problems, barriers and controversies in the way contemporary science is performed are presented by the OS community as an ex negative argument for the strong program. For example, scientific knowledge tends to be exaggerated and inflated in the current system due to the economic landscape of publications, promotion and reputation [Young, 


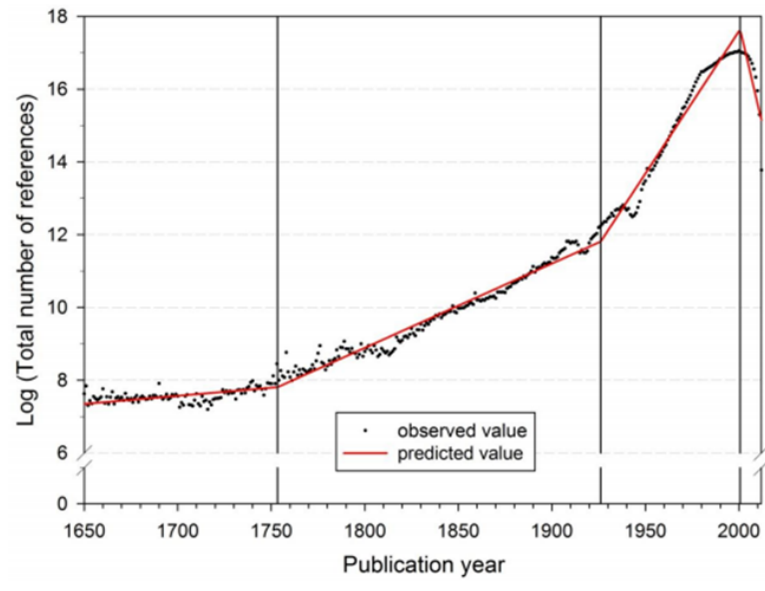

Figure 1. Segmented growth of the annual number of cited references from 1650 to 2012 (citing publications from 1980 to 2012) [Bornmann and Mutz, 2014].

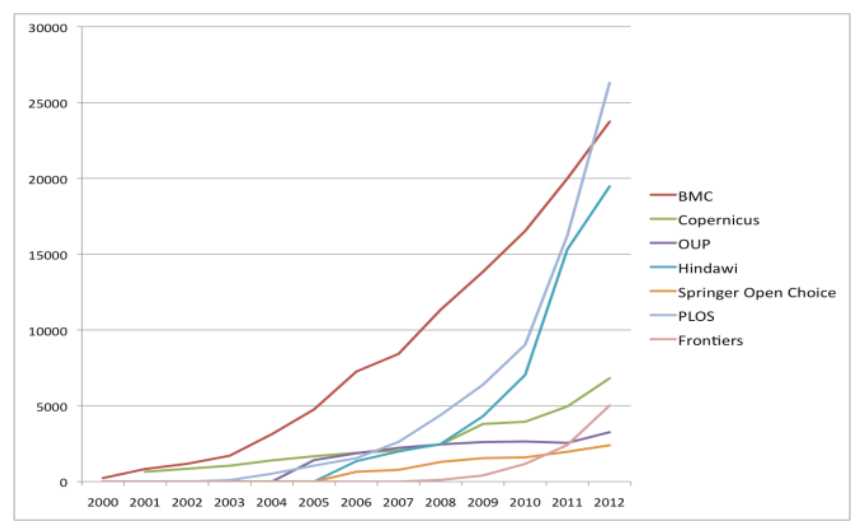

Figure 2. Data on publication volumes for major Open Access publishers [Neylon and OASPA, 2013].

Ioannidis and Al-Ubaydli, 2008; Pedersen and Hendricks, 2013], to the effect that publication retractions have shot up tenfold in the past decade [van Noorden, 2011]. Also, the exponential growth of both traditional and Open Access publications (see figure 1 and 2) creates an overload of information, contributing to simultaneous and repeated discoveries and 'invisible colleges' [Price, 1963]. Adding to this, a wave of criticism has surfaced emphasizing that peer review is slow, non-transparent and inefficient [Smith, 2010], and that large parts of the scientific literature and data go unnoticed and are under-used [Meho, 2007]. Finally, the current "reproducibility crisis" (i.e. the irreproducibility of key experiments in health science and clinical psychology) is seen by the OS community to reflect a more profound lack of openness about methodological information and datasets [Knorr-Cetina, 1981].

The negative argument, however, is only one part of the persuasive force of OS. Positive arguments, on the other hand, make reference to the unprecedented possibilities for collaboration and data-driven research. In a recent paper in Nature, Adams [2013] hypothesizes that the current research system is entering "a fourth age of research" driven by international collaborations between research teams and large-scale digital interaction that radically challenges the nation-state, the institution and even the individual as the primary locus of knowledge production. ${ }^{1}$ The positive argument for the strong program is, therefore, that digital access and data-sharing technologies through new forms of databases, collaborative tools and referencing methods will help the research community deal with the problem of under-used research and improve knowledge acquisition and dissemination [Meho, 2007]. The argument is even stronger than the negative account, since the idea is that the improvement of science will go beyond not only the individual scientist, but academia itself, contributing to problem-solving and impact-oriented solutions in society. The latter also reflects the current uptake of OS initiatives by

\footnotetext{
${ }^{1}$ The study shows that, over more than three decades, domestic output — papers that list authors from only one country - has flat-lined in the US and EU. The rise in total output for each country is due to international collaboration. As a result, the percentage of papers that are entirely domestic is falling. For established economies, total national research output has more than doubled over the past 30 years, while domestic output has increased by only about 50 per cent [Adams, 2013, p. 559].
} 
the science policy community, such as the European public consultation on "Science 2.0" and the subsequent adoption of OS as part of the European Union's framework programme for research and innovation [Moedas, 2015].

At the same time social media and digital online tools are used to create shared communicative spaces in which this amplification of collective learning takes place. For OS, communication and information technologies are socio-technical tools that contribute to reinventing the way in which researchers create knowledge [Nielsen, 2012]. Among the most celebrated examples in the OS literature are examples of Open repository (ArXive), Open Database (SPIRES, GenBank), Citizen Science (Foldit, the Polymath Project, Galaxy Zoo) and Crowdsourcing (InnoCentive). Initiatives such as these show how socio-technical tools have created new platforms for knowledge production and together with an increased societal focus on grand challenges, support OS in a strong and positive way. ${ }^{2}$ However, we must not conflate these examples with Open Science per se, since not all of these cases (for example the Citizen Science cases [Wiggins and Crowston, 2011]) are open for broad-scaled knowledge sharing. Instead, we must question what it means to be open beyond simple notions of Open Access and Open Data.

\subsection{Beyond Open Access}

Historically, the aim of scientific communicating has been to engage with other scientists (see the introductory remarks of the first scientific journal from 1665, Philosophical Transactions, [Oldenburg, 1665]). Etymologically, to communicate means 'to share' (from Latin commûnicâre). But in the last part of the 20th Century, the "who" and the "what" of sharing knowledge has become increasingly narrow. In today's specialized research literature scientists communicate to other scientists about matters of highly specialized knowledge, and with no or little attempt to share knowledge with wider communities within or beyond academia. Often, the sharing of knowledge with those outside the world of research is delegated to science communicators, who struggle to comprehend and reduce the vast complexity of modern science. ${ }^{3}$

Influential attempts to advance OS and to deal with this problem of scientific communication have been initiated by the Open Access (OA) movement (e.g. The Budapest Open Access Initiative). In various ways the transition to OA presents one of the most radical overhauls of academic communication since the introduction of the Internet. Funding agencies such as Welcome Trust and the European Commission have demanded that all research output from their grant

\footnotetext{
${ }^{2}$ Lately, the European Commission has endorsed open science and open innovation at the academic as well as industrial level. Among other things, this has led to the establishment of the EU's Open Innovation Strategy and Policy Group (OISPG) that works with involving citizens directly in the innovation process. The objective is to stimulate government, industry, academic and civil participants to work more closely together to co-create solutions and knowledge beyond the scope of what any one organization or person can do alone (http:/ / ec.europa.eu/digital-agenda/en/ open-innovation-strategy-and-policy-group).

${ }^{3}$ In the traditional deficit model of scientific communication, it is presumed that there is a knowledge deficit in the public that can be 'fixed' by giving the public more information, with scientists assuming that "facts" (whatever they are) will change citizens' views and make them embrace scientific rationality. While this model not only undervalues the public's opinion and knowledge, it also serves to conceal the highly esoteric, closed-minded and technical character of late-modern scientific knowledge production, which is the cornerstone of closed science.
} 
holders is made publicly available, and numerous universities worldwide have announced their intention to demand OA.

However, one of the problems with OA is that it preserves a conservative approach to the dissemination of scientific knowledge. From a Kuhnian perspective, the purpose of science is still very much seen as the attempt to increase knowledge specialization [Kuhn, 2000]. Scientists aim to develop more sophisticated and specialized methodologies, technologies, data, and theories, which are communicated through the traditional medium: journal publications. Familiarity with the specialized terminologies, methods, tools and data are taken for granted, with scientists outside their own discipline having no chance to understand vast parts of the published literature. Even scientists within the same discipline may encounter problems understanding what their colleagues are publishing. For the rest of society it is almost impossible. Thus, publishing in OA journals does not solve the challenge of communicating science for the benefit of society, since openly available knowledge is still comprehensible to only a small minority of specialists.

Another problem for OA is that of collaboration. Since the collaborative processes of OA are limited to that of journal publication, the main indicator of collaboration is co-authorship. It is nothing new that contemporary research is driven by transnational collaborations mediated by digital technology, such as the Internet and social media. Yet, limiting collaboration to that of journal publications not only overlooks the possibilities that new media offer: it also makes it difficult to open up the scientific process and engage scholars and stakeholders outside academia. Due to the communication problems mentioned above, journal publications cause a 'hyper-specialization' that excludes scholars and citizens from many aspects of the scientific process - hence challenging the notion of collaboration [Ito, 2014].

Objective: a 'second wave' Open Science
With numerous policy actors and scientific heavy-lifters now endorsing OS, we believe it is time to question if OS is simply a new scientific ideology - or if OS should be seen as the next major advancement in the production and communication of knowledge. Or to rephrase the issue: what would it take for OS to genuinely 'revolutionize' the scientific practice? To begin with, we understand OS as part of a broader scientific development aided by the provision of communication and information technologies. But the question remains if this evolution can - and must - be pushed further than the current state of OS in order to live up to the name of truly open science.

In order to answer this question, we will distinguish between two waves of OS. Whereas for many actors the first wave of OS was primarily driven by openness in publications, the second wave includes entirely new communication platforms and engagement technologies that extend beyond mere scientific scholarship and scientific data understood as what can be captured in a text. Crucially, second wave OS includes an awareness of "the human factor" of digitally mediated social realities. Opening up the next generation of scientific communication leads to an entirely new way of producing and validating knowledge, such as in direct communication with citizens and patients (citizen science), in the direct sharing of research artifacts (such as code, data, algorithms, ideas, notes, etc.) or in the use of audiovisual media (such as podcasts and films) to capture other forms of embodied data. 
Yet, opening up the research process does not automatically lead to more robust or sound knowledge, as proponents of the strong program believe. Instead, we show how three fundamental challenges need to be addressed in order to harness the full potential of openness without 'openwashing' the social conditions of knowledge:

1. The Challenge of Communication: the current publish-or-perish regime overemphasizes written publication in international journals, which counterproductively eliminates the motivation for utilizing and appropriating means of scientific communication through other modern media.

2. The Challenge of Collaboration: OS requires scientists that are both willing and able to collaborate using online tools and with other end results in mind than journal publications. The current scientific landscape and research education do not provide sufficient incentives and skills for such research practices.

3. The Challenge of Cultivation: a cultural change is needed for the Internet and online tools to be fully incorporated into the knowledge processes of science. This change requires an overall reformulation of how to do science.

\subsection{Opening up the medium}

In this section, we provide a proof-of-concept for practicing open science with other media and data-formats than publications. We call this practice Open Media in order to emphasize the ambition of opening up the media through which scientific knowledge is processed, validated and circulated. Open Media does not aim to abandon the written medium or the journal format, but should rather be understood as a way of dealing with the three challenges of OS presented above, and as a supplement to conventional publication and communication platforms [see also Bourne, 2010]. This means that we take the notion of 'Open Media' to be a subcategory of OS and a way to promote its second wave.

The use of alternative media in fostering OS has already been seen in FoldIt, where experimental research on protein folding used virtual interaction and gamification as a way to cultivate large-scale research collaboration and mass experimentation [Cooper et al., 2010]. Another example of open media is the Journal of Visualized Experiments (JOVE), where scientists upload videos of how their experiments work. Likewise, Nature Publishing Group recently announced a collaborative experiment where the journal authors are asked to produce audiovisual summaries of (selected) research papers [Inchcoombe and Newton, 2015]. Finally, to illustrate that the future of science communication is no longer only about Open Access, but about Open Data and Open Science, PLOS focuses on audiovisual communication by introducing an OpenCon Community Webcast. Together, these examples demonstrate how different media can supplement the scientific process in overcoming the challenges of communication and collaboration.

However, the use of open media in OS immediately leads to the question of validation and evaluation. For centuries, scientific validation and reputation were based on text production and peer review. With the advent of open science and open media, a much wider audience of users and co-producers are invited into the research process, making standard evaluation difficult or even impossible. Hence, it is necessary to further explore how the utilization of open media in open science 
leads to new forms of social validation in which stakeholders and non-peers are invited to take part in the production, authorization and dissemination of research. Open media requires, first of all, a cultural shift in how science is performed, which Nielsen has called "extreme openness" [Nielsen, 2012, p. 183]. In the next sections, we explore what criteria of success and failure look like in the age of open science.

Method: collaboration between science and documentary
In its current form, OS lacks a firm methodology for evaluating what it means to open up scientific research. In this respect, contemporary cognitive science is an instructive example. There exists a long-standing tradition of using cognitive science to understand scientific processes and reasoning [e.g. Giere, 1986; Nersessian, 2006; Thagard, 2012]. Furthermore, studies in the cognitive science of 'collective, group and collaborative intelligence', 'crowd and group behavior', and 'group and collective decision-making' have already been an influential inspiration for OS [e.g. Nielsen, 2012].

In the following, we will use cognitive science to discuss open media and as a test bed for new types of open collaboration between scientists and documentary filmmakers. We will look at two cases of such collaboration, and discuss whether such initiatives are able to deal with the challenges of communication, collaboration and cultivation. This narrative should be seen as a way to help provide a better and more comprehensive understanding of the behavior, practice and attitudes needed to stimulate the next wave of open science.

\subsection{A preliminary experiment}

A documentary is a nonfictional film intended to document aspects of reality, first and foremost for the purposes of illuminating particular societal or historical records. Documentary filmmaking has been used as a data-collecting tool in scientific disciplines and the educational and social sciences. In the human and social sciences it has even been argued that documentary filmmaking can be integrated as a new methodology for doing science. Not only do documentaries make the distribution and communication of results accessible to external audiences, but including documentary filmmakers in the research process also leads to scientists' asking new and different questions, and changes the observational stance of science. Precisely because documentaries comprise both the co-creation and dissemination of research, and filter the scientific view through an external observer, we turn to documentary filmmaking as a source of inspiration for open media science.

An example from our own experiments with open media research is a collaborative project with the Danish Film Institute, Creative Europe Media Desk, and the production company Final Cut 4 Real. In 2014, we arranged a workshop with 50 scientists, film-directors and producers in Denmark with the purpose of discussing and exploring the possibility of creating a new collaborative methodology for enhancing the conversation between science and documentary filmmaking. During the workshop we interviewed a number of scientists ${ }^{4}$ and filmmakers ${ }^{5}$ about their

\footnotetext{
${ }^{4}$ Leif Oxenløwe, Professor of photonics, David Budtz Pedersen, Associate Professor of philosophy, Andreas Roepstorff, Professor of anthropology, and Birger Møller, Professor of synthetic biology.

${ }^{5}$ Phie Ambo, director of Free the Mind, Janus Metz, director of Armadillo, and Joshua Oppenheimer, director of The Act of Killing and The Look of Silence.
} 
experiences with and expectations of collaborating with each other. ${ }^{6}$ The general conclusions of the interviews were:

1. Scientists are concerned with how their work is communicated through news, entertainment and mass media.

2. Documentary films are not the same as news, entertainment or mass media.

3. In some cases, there are more parallels and similarities than differences in the way that scientists and documentary filmmakers work.

4. Many researchers are open to including documentary films in the research process and using them as a way of communicating research results.

Following these observations, we sat up two experiments to test whether it was possible to use documentary films in real-time as part of one's research methodology and explorative process.

Results: Natural Disorder and Collaboration
The first experiment resulted in the documentary film, Natural Disorder, directed by Christian Sønderby Jepsen. The film is about Jacob Nossell, who lives with cerebral palsy $(\mathrm{CP})$, the most common type of disorder associated with congenital motor impairment [Aisen et al., 2011]. CP is a group of disorders in the development of postural and motor control, occurring as a result of a non-progressive lesion in the developing central nervous system and causing activity limitations [Bax et al., 2005]. With Kristian Moltke Martiny as lead, the documentary, which seeks to address the complexity of living with $\mathrm{CP}$, is comprised of a series of conversations with a number of scientists. By closely following Nossell and communicating his perspective in a narrative that is understandable for others, the film becomes a quest for understanding what it means to live with $\mathrm{CP}$ from his first-person perspective. The film premiered in Danish Cinemas in October 2015 and internationally at the International documentary festival Amsterdam (IDFA) in November 2015.

The second experiment was the documentary film, Collaboration - On the Edge of a New Paradigm? This experiment was carried out by Alfred Birkegaard as an explorative method to investigate the impact of the Internet and online collaboration on the scientific community by interviewing some of the world's most prominent researchers in the field. The documentary dealt with interdisciplinary, legal, and practical dimensions of collaborative research by engaging with scientists across the humanistic, natural and technical sciences. The film was shown at the documentary film festival CPH:DOX in October 2014 and on Danish national television in May 2015 (it was released under creative commons and can be streamed for free). ${ }^{7}$

In both experiments the documentary films were not designed as traditional science documentaries depicting the practice of science, but instead as open media

\footnotetext{
${ }^{6}$ The full interviews can be seen here (collaborativesociety.org), and a summary of the interviews can be seen here (scienceXcinema).

${ }^{7}$ The film can be screened in open access here: Collaboration.
} 
experiments where the films became the practice of science itself. ${ }^{8}$ Natural Disorder was operating with two hypotheses: 1 ) documentary is a way of practicing collaborative knowledge production that genuinely embraces the complexity of living with $\mathrm{CP}$, and 2) documentary is a way of communicating this complexity to a non-specialist audience. As such, the film tries to deal with the challenge of both collaboration and communication, while also demonstrating their intrinsic interrelation.

Just as with the first experiment, Collaboration tries to deal with the challenge of collaboration and communication, and demonstrates their intrinsic interrelation. To do so, the aim was to investigate if researchers without any prior schooling could adopt untraditional media, such as documentary filmmaking, as part of the exploratory process. In this case the documentary was used as a method for investigating the topic of collaboration while engaging with real-world research practitioners. The purpose was not only to understand and present how contemporary collaborative research affects scientific practices worldwide, but also to provide examples of how to engage in collaboration and involve researchers and practitioners in a shared exploratory space. The documentary film was a way to experiment with the practice of collaborative science and it operated with two hypotheses: 1) documentary can be used as a methodology for producing real-time interfaces between scientists, citizens and filmmakers, and 2) documentary is a way of engaging in collaborative research in a meaningful and substantial way.

Discussion: the challenge of collaboration and communication
Both of the experiments deal with the challenge of collaboration and communication in practicing open science. In the following we discuss the use of documentary films in the scientific process as a way to explicitly face these two challenges.

\subsection{Natural Disorder: post-disciplinary engagement}

To assess to which extent Natural Disorder (2015) addresses the challenge of collaboration and communication, we need to give a brief sketch of the current research in disability and cognitive science. Following the International Classification of Functioning (ICF), the WHO has promoted a "bio-psycho-social model" that interprets disability as a dynamic and complex interaction of health (biological) conditions, personal (psychological) and environmental (social) factors [WHO, 2011; ICF, 2001]. Since CP is a heterogeneous and complex condition that varies according to the particular brain lesion and individual, performing a bio-psycho-social diagnosis or treatment is the ideal aim of $\mathrm{CP}$ habilitation research. In other words, the aim of CP research is to address the 'whole,' 'unique', and 'individual' person living with CP. To do so would require engaging scientists and professionals from many different disciplines such as neurology, pediatrics, psychology, physiotherapy, occupational therapy, pedagogy and educational sociology. Collaboration on this scale is challenging, since the different scientists and professionals use different specialized terminologies, methods and tools, and ultimately have different criteria for diagnosing, treating and habilitating CP.

\footnotetext{
${ }^{8}$ Thanks to one reviewer for making us clarify this point more thoroughly.
} 
In cognitive science, Roschelle and Teasley [1995] have famously distinguished 'cooperative' from 'collaborative' problem solving by distinguishing between a group of individuals solving distinct components of a problem and individuals who collectively solve a problem. The latter implies a collaborative process and can be seen as an activity of mutual engagement between individuals who share an emergent, socially-negotiated set of beliefs. These beliefs together with the material conditions under which they are expressed constitute what Teasley and Rochelle call a Joint Problem Space (JPS), which is the medium through which collaboration can occur [Roschelle and Teasley, 1995, p. 71].

What this means is that diagnosing, treating and habilitating persons with $\mathrm{CP}$ calls for an interdisciplinary process embedded in an external medium so as to enable the construction of a shared, emergent, and socially-negotiated space in which patients, scientists and citizens can take part. Written media - for example journal papers - have difficulties establishing such a shared space, not only because of disciplinary specialization and technical terminology, but also because of the restricted phenomenological qualities of texts and datasets. Publications simply represent a poor medium for engaging with patients, since they don't involve a social and material space in which to engage and create meaning. Video and filmmaking, on the other hand, make it easier for the patient to interact and produce meaning even at the most superficial level. They can also be used as an observational and diagnostic medium for $\mathrm{CP}$, utilizing software programs and other visual representations to increase the reliability of the video analysis [Adde et al., 2010; Borel, Schneider and Newman, 2011; Harvey and Gorter, 2011].

Importantly, support for this approach can be found within cognitive science itself in the so-called Embodied Cognition (EC) literature, which is known for its critical attitude towards the 'observational and spectator stance' in understanding cognition. EC aims to introduce an interactive turn in contemporary cognitive science and hence develop a second-person study of cognition [Thompson, 2001], which includes aspects of experiential and emotional engagement and dynamic and reciprocal interaction [Schilbach et al., 2013; Satne, 2015]. As demonstrated by Natural Disorder, video documentation can play an important role in creating such second-person studies of cognition, while at the same time refraining from 'reifying' observational data about human behavior, interaction and engagement.

Following this line of argument, video is a medium for scientists to both interact and engage with each other as well as corroborate data. In contrast to the written medium, video introduces unique potentials for science, as Roschelle [1998] points out: 1) video enables the scientist to preserve audiovisual data of human behavior and interaction, such as voice, the use of voice (paralanguage), bodily and facial gestures, touch, eye gazing, mimicking, social context, etc. Video documentation can be used to avoid the problem between 'what I say' and 'what I do' that can occur in self-reports. 2) Repeated viewing of a specific scene can lead to complex insights that cannot be gained from textual transcription of the same scene.

3) Video supports interpretations from many frames of analysis, and can be used as a common medium for rich multidisciplinary analysis. 4) Video can be shared with the participants in it so as to acquire the participants' own perspective on their behavior [Roschelle, 1998, pp. 727-728]. 
Natural Disorder served as an open medium for collaboration between neuroscientists, psychologists, philosophers, and researchers in bioinformatics and geogenetics, and for Nossell himself as he underwent a number of studies from MR-scanning, DNA-testing and motion-capture to different social experiments. All of this is captured by the film in order to present a complex real-world picture of what it means to live with CP. When the director finished editing the film, several scenes were presented at international conferences and workshops in cognitive science and disability studies. In doing so, the data was opened up to multiple interpretations and analyses. In some cases the documentary scenes were presented together with Nossell in order to get his perspective on his experiences shown in the film.

Thus, the process of making and discussing the documentary became a medium for opening up data and creating a collective understanding that not only included other scientists, professionals and Nossell himself, but that ultimately made the complexity of living with $\mathrm{CP}$ assessable to a wide audience of cinemagoers and television viewers. The experiment also demonstrated that scientists are not foreigners to open media. They already use visual tools such as pictures, diagrams, and imaging techniques to designate statistical relations and depict scientific models of e.g. DNA structures or neural circuits.

\subsection{Collaboration: questions of practical knowledge}

As mentioned above, collaboration is the main focus of OS and plays an important function in almost every part of contemporary science [Adams, 2013; Bozeman and Boardman, 2014; Pedersen, 2015]. As we saw in the example of Natural Disorder, the medium of documentary filmmaking is one way to open up the research process and create a joint problem space that enables shared understanding between different scientists and audiences. In the second film Collaboration (2014), the question of what scientific collaboration can mean was explored by opening up the workflow [Bourne, 2010] through recording interviews and conversations with scientists - and furthermore by feedback-looping the process by showing the scientists their own interviews, thus creating real-time conversations in the filming process.

One example of such feedback is an interview with the philosopher Hubert Dreyfus, who has been one of the most prominent advocates of the embodied cognition hypothesis. In the interview, Dreyfus clarifies a fundamental point of embodied cognition, namely that knowledge processes are not about having the right rules in your mind or simply reflecting on, thinking about, memorizing or asking 'why' questions. According to the embodied cognition approach, it is necessary to distinguish between the cognitive processes of 'I think' and 'I can'. The latter is a question of 'know how', which relies on experience, learning by taking risks and making mistakes. It involves intuition and dynamic interactions in order to affect knowledge [see Dreyfus, 1972; Dreyfus, 1992].

In this respect, the making of documentary films becomes a relevant learning tool that can enhance and further develop the OS movement. Roschelle argues that video is a beneficial method of data collection in educational and social science, since it enables researchers to leave the laboratory behind and conduct fieldwork, 
where one can engage with one's research topic in a contextualized way. Instead of relying solely on video, the researcher should utilize a triangulation of data including interviews, journals and observations [Roschelle, 1998, p. 725]. ${ }^{9}$

In the process of making Collaboration, new data and insights were produced as a foundation for understanding the challenge of how to collaborate. However, the challenge of collaboration is not simply to find scientists who are willing to collaborate. It is also to highlight, discuss and challenge the skills necessary for engaging in collaboration. Whereas classical scientific training leads to a predominantly reflective 'I think' attitude, which is the basis of specialized and decontextualized knowledge [Gallagher and Marcel, 1999; Donaldson, 1978], the skills needed for collaboration cannot be reduced to specialized or formal knowledge. Rather, collaborative skills need to be added to the repertoire of scientific skills so as to avoid 'openwashing' the knowledge process.

Again, the cognitive science community presents a good example. The so-called Open MIND Project (http:/ / open-mind.net/about), launched in 2014, attempts to promote a new collaborative horizon for researchers working in cognitive science. In short, the Open MIND project infuses the Open Science movement with cognitive science by devising a series of experiments with open access and open peer review. Metzinger and Windt's seminal paper describes what it means to be "open-minded" as an epistemic practice for approaching ideas, topics, theories, methods, and fellow researchers [Metzinger and Windt, 2015]. Importantly, this "open mindset" is not reducible to a theoretical attitude towards science, and even less so to a strategic or instrumental attitude oriented towards maximizing research outputs [Metzinger and Windt, 2015, p. 23]. Rather, the aim is to ask critical questions, to challenge or reject prior commitments, and to highlight ambiguity and the possibility of falsification as indicators of scientific success [Frodeman, 2014]. To embrace this attitude is not to accept that 'anything goes'. Having an open mind in science is about the emergence of a new type of scientist. In connection with cognitive science, OS requires real scientific and extra-scientific skills, and hence a new way of producing and communicating science. ${ }^{10}$

In the film Collaboration, Douglas Thomas, a professor of communication at the University of Southern California, highlights the distinction between explicit and tacit knowledge, and emphasizes that "in the $21^{\text {st }}$ Century the tacit is becoming more and more important." According to Thomas, this requires that education change from mechanistic learning — transferring specialized knowledge from teacher to student - to focusing on contextualized, tacit and dynamic knowledge [see also Thomas and Brown, 2011]. Many different terms have been used to describe this 'tacit' form of knowledge, such as 'practical knowledge', 'know how', and 'experience', all of which are typically difficult to conceptualize and verbalize. Accordingly, this kind of knowledge is typically labeled 'pre-reflective' in the cognitive science literature [Gallagher, 2005; Gallagher and Zahavi, 2008]. If this

\footnotetext{
${ }^{9}$ In addition to the interviews conducted in the film, the documentary also features an observational study of collaboration between the Danish biotech company Novozymes and the biohacking space Labitat. In this specific case, Novozymes entered into collaboration with Labitat to find synergetic effects while developing new tools for measuring bioethanol during fermentation.

${ }^{10}$ Several initiatives already exist that aim at educating a new generation of open scientists. For instance, the Open Science Resources (OSR) is a collaborative project co-funded by the European Commission under the eContentplus program with the purpose of developing a shared digital repository for formal and informal science education.
} 
shift towards the tacit dimension of knowledge is taken seriously, it lends a crucial role to other media and data than textual artifacts in education and teaching. Communicating tacit knowledge is exactly one of the perceived benefits of video, which has been used for a long time as a way to acquire informal and pre-reflective knowledge [e.g. Sherin and van Es, 2005; see also Kraker et al., 2011, p. 647]. ${ }^{11}$

\subsection{We-experiences}

The advantages of online platforms and social media are typically described by OS advocates as a 'game changer' for doing science. OS scholars aim at combining open access with social media, which is the "fluid realm of websites, blogs, file sharing, and social networking: the dynamic, unmediated, uninhibited, and challenging domain of 'Web 2.0"' [Grand et al., 2012, p. 683]. But no matter how many tweets or blog posts a scientist writes, a much greater deal of work will need to be done to proactively embrace the pre-reflective and tacit aspects of knowledge described above. In other words, aspects of body language, gestures, mimicking, emotions, haptic engagement, context, etc. need to be integrated into the communicative sharing of a "we-experience" that extends beyond the realm of the laboratory and produces a situation in which "collaborators [are] for each other in consummate reciprocity" [Merleau-Ponty, 1962/2002, p. 413].

The strength of online social media such as Instagram, Snapchat or Youtube is precisely captured by their ability to share pre-reflective processes through audiovisual representations of embodiment and situated experiences. This also holds for documentary films. The meaning communicated through pictures or videos is immediate, transparent, and universal.

This sharing of knowledge that is understandable outside academia is especially important in the case of health science, where persons living with a disease, disorder or disability should be considered as agents in their own treatment. The example of biotech entrepreneur Hugh Rienhoff and his daughter Bea is a case in point (Rienhoff and Bea are interviewed in Collaboration). Bea was born with a congenital defect that resisted satisfactory diagnosis and remained elusive.

Rienhoff bought secondhand DNA sequencing equipment and started to look for a diagnosis himself, frustrated by his daughter's situation. He succeeded: through exome sequencing, he revealed that Bea's condition was genetic, not inherited, and originated in herself as a de novo mutation [Rienhoff et al., 2013].

This case is typically used to promote do-it-yourself (DIY) genetics, personalized genomics and citizen science, but Rienhoff acknowledges that his mission wasn't just to diagnose Bea, but in fact to empower others: "I'm interested in cases of altruists who, rather than hiding from genetics, are using the opportunity to be sort of social activists, working to raise consciousness and maybe raise money for diseases affecting their family and friends" [Maher, 2007; see also Maher, 2013].

The case is exceptional and controversial, since it might lead other parents down a wrong path, searching for alternative treatments instead of providing proper health

\footnotetext{
${ }^{11}$ The use of video for educational purposes is also emphasized in online and virtual universities (Open Educational Resources), and is further exemplified in the growing use of YouTube tutorials to gain specific skills or knowledge.
} 
care [Maher, 2007]. Nevertheless, the aim of empowering others through open source technologies and media is a strong case for open science. Sharing life experiences with others, which was one of the incentives for making Natural Disorder, can both increase a person's understanding and acceptance of her situation by offering new worldviews and provide role models for different ways of coping with the situation, seeing alternative perspectives, and allowing for learning, modeling, and enhancing problem-solving skills [Davidson et al., 1999, p. 168; Davidson et al., 2012].

\subsection{Global knowledge sharing}

The power of science-based documentary films is their ability to convey a sense of shared experiences and integrate multiple worldviews and alternative perspectives into the scientific process. With the proliferation of affordable audiovisual recording and streaming technologies the potential reach of scientific documentary films is unlimited. By using creative commons, Collaboration has been released on different platforms such as documentaryheaven.com and several other websites. As this article is being written, the documentary has been downloaded 98.514 times, played 21.751 times and streamed in more than 150 countries (see figure 3).

It is not up to us to assess if the two documentary films presented and analyzed in this article were successful, or whether they were able to convey and co-produce new scientific knowledge. However, both Natural Disorder and Collaboration are examples of science-based documentaries that have demonstrably engaged people from both inside and outside academia with the effect of "opening up" research processes that would otherwise have been closed and inaccessible to wider audiences. The same results could possibly have been obtained by using other media and formats such as radio, theatre, photography etc. The mark of success for Open Media is access to embodied and situated experiences, which combine the pre-reflective gaze of real-world living conditions with the theoretical and formal aspects of scientific knowledge and expertise.

Conclusion: how to cultivate open media?
In this article we have presented a proof-of-concept for open media, which should be seen as an addition and supplement to the already-established six open aspects of methodology, source, data, peer review, access and educational resources. By presenting and discussing two experiments in science and documentary filmmaking we have argued that open media has the potential to deal with the challenges of communication and collaboration. However, Rochelle has stated that a "research video is not like a research paper because a research video lacks a commonly understood genre" [Roschelle, 1998, p. 723]. Developing such a genre is part of the last challenge of OS, that of cultivation.

Scientists are known to have, and should have, concerns about how they and their work are presented in the media [Suleski and Ibaraki, 2010]. What the two examples show is that a new set of ethical and normative standards is required for open-minded scientists to navigate in such a complex and distributed social field as open media. Scholars advocating OS are regularly talking about cultivating a new collaborative mindset for doing science [e.g. Hampton et al., 2015]. This cultural change is the 'hard problem' of OS, since it demands a change in the minds of 


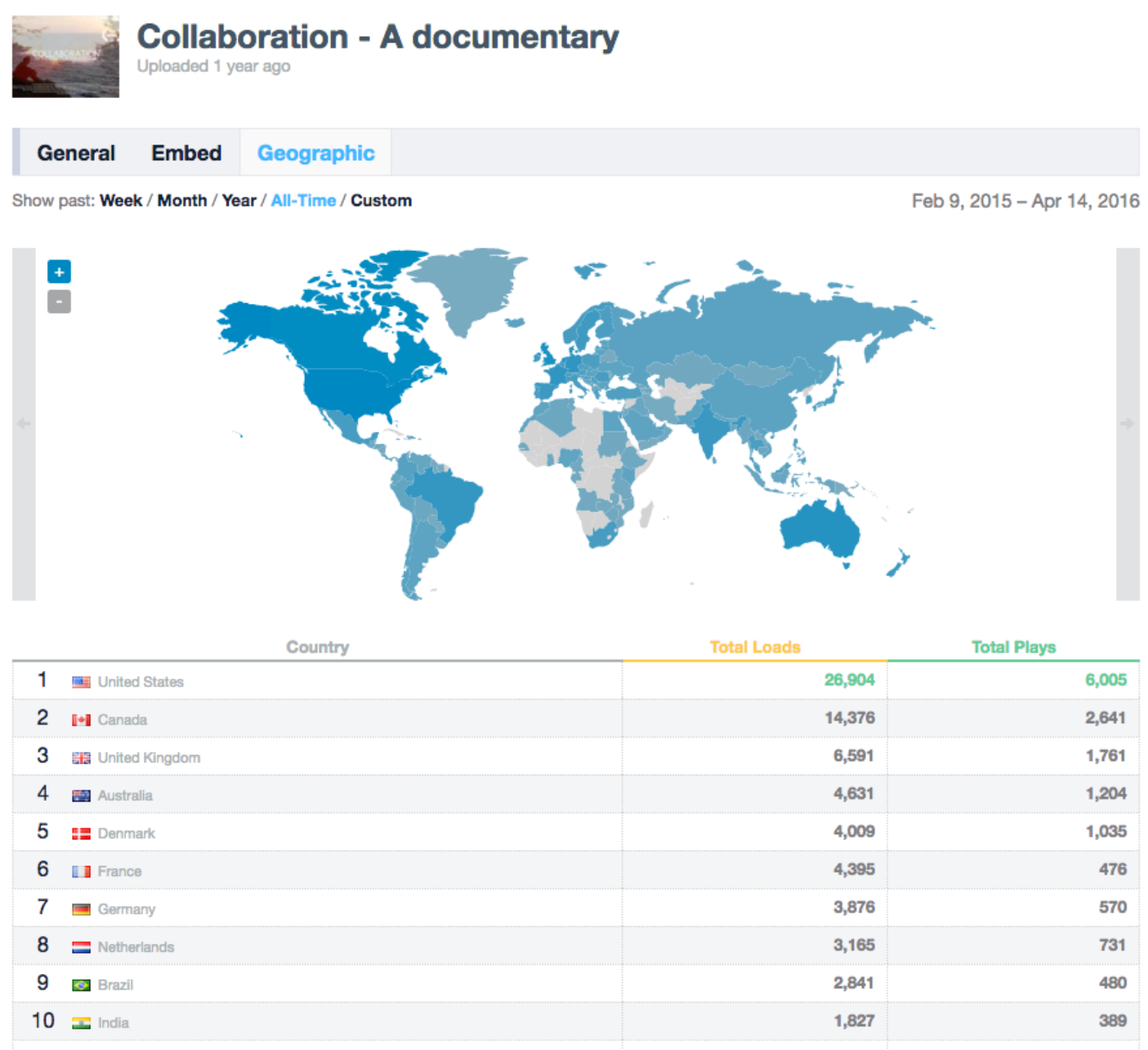

Figure 3. The ten countries that have loaded or played Collaboration the greatest number of times; illustrated in color by lower (grey) to higher (dark blue) number of total loads and plays.

scientists. Changing a mindset into a collaborative mind- and skillset is not something that can be done strategically or by theoretical operations alone. It's something that relies on education and know how, and that can only be done by actively working together. Open media efforts also need new systems of assessment and evaluation that take collaboration seriously. This change requires that we understand "science as a dynamic, tentative, uncertain, and constantly revised activity" [Grand et al., 2012, p. 681], rather than as a merely definitive set of experiments with polished results.

What does this mean for the evaluation and validation of open media science? First of all, it means understanding scientific validation as more than just a correspondence theory of truth and a therefore a relation between model and world. Consistency of data and predictions continues to be a good indicator of robust scientific theories, but such representational qualities cannot stand alone in open science. Following discussions in embodied cognition, accepting a traditional objective view of science makes us misunderstand and/or overlook data that present subjective, pre-reflective and tacit aspects of knowledge [Varela, 1996; Gallagher and Zahavi, 2008, chapter 2]. The nature of such data, also called 
first-person or phenomenal data, is not static, object-like, or has a fixed diachronic stability, but instead open, dynamic, transparent and something that is embodied, enacted and generated in the world together with other subjects. The methodological challenge is therefore not to end up objectifying this form of data, while at the same time not end up with a contingent and subjective method for validating the data.

Understanding such form of first-person data requires methods fundamentally different from those employed in understanding objects. It's outside the scoop of this paper to describe the different attempts in the cognitive science literature that aims to develop such a method for understanding first-person data [e.g. Varela, 1996; Petitmengin, 2006; Petitmengin and Bitbol, 2009; Høffding and Martiny, 2015]. However, one common and crucial point that the attempts share is that validation is a socially performative and pragmatic process, highlighting the importance of "intersubjective validation" [Varela and Shear, 1999, p. 10], or "intersubjective corroboration" [Gallagher and Zahavi, 2008, pp. 29-31]. This means that besides representational qualities, the process of producing and validating knowledge demands a collective process, something scientists create in collaboration, and which can under the right circumstances include non-scientists and stakeholders as well.

The idea that validation is a performative process should be true for any scientific method, and there should be what Petitmengin and Bitbol call 'performative consistency", which "consists of an agreement among a) the theories, b) the construction of devices and the understanding of their functioning, c) the theoretical guidance of measurements, and d) the results [Pickering, 1995]" [Petitmengin and Bitbol, 2009, p. 391]. They contrast the method for understanding first-person data with examples of astronomy and neuroscience and argue that, even in these 'objective' sciences, researchers only have access to and engage with the 'data' through instruments and recordings, meaning that they don't have access to the actual astronomical events or the activity of the brain as such. It is tempting to think that, when scientists give convincing explanations, those explanations are validated through a correspondence between the theory and its external object. However, what is in fact the case, they argue, is that the explanation is validated through performative consistency. Following this understanding of scientific validation, what then needs to be developed in future research of open media is the criteria for performative consistency when using a medium other than text for dealing with first-person data.

There is also no easy way to measure the success of Open Media Science. While platforms such as Altmetrics are important to OS, the number of likes, shares, retweets or upvotes cannot stand alone as indicators of valid knowledge. Instead evaluation methods need to be open-ended themselves, hence living up to the mantra of open science. This includes, for example, experiments with open peer review and open data. Already today, platforms such as Datadryad.org, Myexperiment.org, Figshare.com, Sci-starter.com and Runmycode.org make it possible to collect, analyze and disseminate open scientific data, and at the same time provide the users with information about the quality and impact of the data. But, as we have argued in this article, it should not be scientists alone that participate in such dynamic evaluation of data, but a broader public of creative and curious individuals. 
The peer review model is also changing. Experiments with post-publication commenting, post-publication review, community-based review, comment crowdsourcing and invited moderation are just some of the examples of new models of peer review that are currently being tested [Shashok, 2010; Pickard, 2012]. In this new model, "publish or perish" is slowly being substituted by "getting visible or vanish" [Enzor, 2012]. We have scrutinized the notion of visibility in this paper and argued for transitioning into an Open Media Science. The idea of open media requires further development, but the ideal aim is to open-mindedly start creating a dynamic, shared and collaborative knowledge community.

\section{References}

Adams, J. (2013). 'Collaborations: The fourth age of research'. Nature 497 (7451), pp. 557-560. DOI: 10.1038/497557a.

Adde, L., Helbostad, J. L., Jensenius, A. R., Taraldsen, G., Grunewaldt, K. H. and Stø en, R. (2010). 'Early prediction of cerebral palsy by computer-based video analysis of general movements: a feasibility study'. Developmental Medicine and Child Neurology 52 (8), pp. 773-778. DOI: 10.1111/j.1469-8749.2010.03629.x. PMID: 20187882.

Aisen, M. L., Kerkovich, D., Mast, J., Mulroy, S., Wren, T. A. L., Kay, R. M. and Rethlefsen, S. A. (2011). ‘Cerebral palsy: clinical care and neurological rehabilitation'. The Lancet. Neurology 10 (9), pp. 844-852. DOI: 10.1016/S1474-4422(11)70176-4. PMID: 21849165.

Allen, P. (2011). 'Why We Chose 'Open Science'. Wall Street Journal. URL: http: //ww w.wsj.com/articles/SB10001424052970204630904577058162033028028.

Bax, M., Goldstein, M., Rosenbaum, P., Leviton, A., Paneth, N., Dan, B., Jacobsson, B., Damiano, D. and Executive Committee for the Definition of Cerebral Palsy (2005). 'Proposed definition and classification of cerebral palsy, April 2005'. Developmental Medicine and Child Neurology 47 (8), pp. 571-576. PMID: 16108461.

Borel, S., Schneider, P. and Newman, C. J. (2011). 'Video analysis software increases the interrater reliability of video gait assessments in children with cerebral palsy'. Gait $\mathcal{E}$ Posture 33 (4), pp. 727-729. DOI: $10.1016 / \mathrm{j}$.gaitpost . 2011.02.012. PMID: 21420864.

Bornmann, L. and Mutz, R. (2014). 'Growth rates of modern science: A bibliometric analysis based on the number of publications and cited references'. arXiv: 1402.4578.

Bourne, P. E. (2010). 'What Do I Want from the Publisher of the Future?' PLOS Comput Biol 6 (5), e1000787. DOI: 10.1371/journal .pcbi. 1000787.

Bozeman, B. and Boardman, C. (2014). Research Collaboration and Team Science. A State-of-the-Art Review and Agenda. Heidelberg New York Dordrecht London: Springer International Publishing. DOI: 10.1007/978-3-319-06468-0.

Budapest Open Access Initiative (2002). Read the Budapest Open Access Initiative. Open Society Institute website.

URL: http://www . budapestopenaccessinitiative.org/read.

Cooper, S., Khatib, F., Treuille, A., Barbero, J., Lee, J., Beenen, M., Leaver-Fay, A., Baker, D., Popović, Z. and Players, F. (2010). 'Predicting protein structures with a multiplayer online game'. Nature 466 (7307), pp. 756-760.

DOI: $10.1038 /$ nature09304. 
David, P. A. (2004). 'Understanding the emergence of 'open science' institutions: functionalist economics in historical context'. Industrial and Corporate Change 13 (4), pp. 571-589. DOI: $10.1093 /$ icc/dth023.

Davidson, L., Chinman, M., Kloos, B., Weingarten, R., Stayner, D. and Tebes, J. K. (1999). 'Peer Support Among Individuals With Severe Mental Illness: A Review of the Evidence'. Clinical Psychology: Science and Practice 6 (2), pp. 165-187. DOI: 10.1093/clipsy.6.2.165.

Davidson, L., Bellamy, C., Guy, K. and Miller, R. (2012). ‘Peer support among persons with severe mental illnesses: a review of evidence and experience'. World Psychiatry 11 (2), pp. 123-128. PMID: 22654945.

URL: http://www.ncbi.nlm.nih.gov/pmc/articles/PMC3363389/.

Donaldson, M. (1978). Children's Minds. Glasgow, U.K.: Fontana Press.

Dreyfus, H. L. (1972). What Computers Can't Do. New York, U.S.A.: MIT Press.

- (1992). What Computers Still Can't Do. New York, U.S.A.: MIT Press.

EC (European Commission) (2014). Public Consultation on Science 2.0: Science in Transition. Brussels, Belgium. URL: http://ec .europa.eu/research/consultat ions/science-2.0/consultation_en.htm.

Enzor, C. (2012). Get Visible or Vanish: Digital Publishing for Science Professionals. ScienceOnline. URL: https : / www . youtube . com/watch?v=f s4mZrxl7gg.

Frodeman, R. (2014). Sustainable Knowledge. London, U.K.: Palgrave Macmillan. DOI: $10.1057 / 9781137303028$.

Gallagher, S. and Marcel, A. (1999). 'The self in contextualized action'. Journal of Consciousness Studies 6 (4), pp. 4-30.

Gallagher, S. (2005). How the Body Shapes the Mind. Oxford; New York: Clarendon Press.

Gallagher, S. and Zahavi, D. (2008). The Phenomenological Mind: An Introduction to Philosophy of Mind and Cognitive Science. 2nd ed. New York, U.S.A.: Routledge.

Geoghegan-Quinn, M. (2014). Science 2.0: Europe can lead the next scientific transformation. Keynote lecture. EuroScience Open Forum, Copenhagen 24 June 2014. Brussels, Belgium.

URL: http://europa.eu/rapid/press-release_SPEECH-14-489_en.htm.

Giere, R. N. (1986). 'Cognitive Models in the Philosophy of Science'. PSA:

Proceedings of the Biennial Meeting of the Philosophy of Science Association 1986 (2), pp. 319-328. URL: http://www. jstor.org/stable/192810.

Grand, A., Wilkinson, C., Bultitude, K. and Winfield, A. F. T. (2012). 'Open Science: A New “Trust Technolog"?' Science Communication 34 (5), pp. 679-689. DOI: $10.1177 / 1075547012443021$.

Hampton, S. E., Anderson, S. S., Bagby, S. C., Gries, C., Han, X., Hart, E. M., Jones, M. B., Lenhardt, W. C., MacDonald, A., Michener, W. K., Mudge, J., Pourmokhtarian, A., Schildhauer, M. P., Woo, K. H. and Zimmerman, N. (2015). 'The Tao of open science for ecology'. Ecosphere 6 (7), Article 120, pp. 1-13. DOI: $10.1890 / E S 14-00402.1$.

Harvey, A. and Gorter, J. W. (2011). ‘Video gait analysis for ambulatory children with cerebral palsy: Why, when, where and how!' Gait $\mathcal{E}$ posture 33 (3), pp. 501-503.

Høffding, S. and Martiny, K. (2015). 'Framing a phenomenological interview: what, why and how'. Phenomenology and the Cognitive Sciences, pp. 1-26. DOI: $10.1007 / \mathrm{s} 11097-015-9433-z$.

ICF (The International Classification of Functioning) (2001). Disability and Health. Geneva, Switzerland: World Health Organization. 
Inchcoombe, S. and Newton, H. (30th July 2015). Explaining scientific research: introducing audio-visual summaries. Of Schemes and Memes Blog, Nature. URL: http://blogs . nature.com/of schemesandmemes/2015/07/30/explaining -scientific-research-introducing-audio-visual-summaries.

Ito, J. (2nd October 2014). Antidisciplinary. Working Paper. URL: http://joi.ito.com/weblog/2014/10/02/antidisciplinar.html.

Knorr-Cetina, K. D. (1981). The manufacture of knowledge: An essay on the constructivist and contextual nature of science. Oxford, U.K.: Pergamon Press.

Kraker, P., Leony, D., Reinhardt, W. and Beham, G. (2011). 'The case for an open science in technology enhanced learning'. International Journal of Technology Enhanced Learning 3 (6), pp. 643-654.

Kuhn, T. S. (2000). The Road since Structure. Chicago, U.S.A.: The University of Chicago Press. URL: http://www.press . uchicago .edu/ucp/books/book/chica go/R/bo3639271.html.

Maher, B. (2007). 'Personal genomics: His daughter's DNA'. Nature News 449 (7164), pp. 773-776. DOI: 10.1038/449773a.

- (2013). 'Father's genetic quest pays off: mutation provides clue to daughter's undefined syndrome'. Nature 498 (7455), pp. 418-419. DOI: 10.1038/498418a.

Meho, L. I. (2007). 'The rise and rise of citation analysis'. Physics World 20 (1), p. 32. DOI: $10.1088 / 2058-7058 / 20 / 1 / 33$.

Merleau-Ponty, M. (1962/2002). Phenomenology of perception. London, U.K.: Routledge and Kegan Paul, Routledge Classics Edition.

Metzinger, T. and Windt, J. M. (2015). 'What Does it Mean to Have an Open MIND?' In: Open MIND. Ed. by T. Metzinger and J. M. Windt. Frankfurt am Main, Germany: MIND Group.

Moedas, C. (22nd June 2015). Open Innovation, Open Science, Open to the World. European Commission - Speech.

URL: http://europa.eu/rapid/press-release_SPEECH-15-5243_en.htm (visited on 16th February 2016).

Molloy, J. C. (2011). 'The Open Knowledge Foundation: Open Data Means Better Science'. PLOS Biol 9 (12), e1001195. DOI: 10.1371/journal.pbio.1001195.

Nersessian, N. J. (2006). 'The Cognitive-Cultural Systems of the Research Laboratory'. Organization Studies 27 (1), pp. 125-145. DOI: $10.1177 / 0170840606061842$.

Neylon, C. and OASPA (2013). 'Growth of Open Access - Major Publishers'. Figshare. DOI: $10.6084 / \mathrm{m} 9$.figshare.650799.

Nielsen, M. (2011). An informal definition of open science. The OpenScience Project. URL: http: //www . openscience. org/blog/?p=454.

- (2012). Reinventing Discovery: The New Era of Networked Science. Princeton, U.S.A.: Princeton University Press.

Oldenburg, H. (1665). 'Epistle Dedicatory'. Philosophical Transactions 1 (1), rstl.1665.0001. DOI: 10.1098/rstl.1665.0001.

OpenScience ASAP. Was ist Open Science. URL: http://openscienceasap.org/open-science/.

Pedersen, D. (2015). 'Collaborative Knowledge: The future of the academy in the knowledge-based economy'. In: On the Facilitation of the Academy. Ed. by E. Westergaard and J. Wiewiura. Rotterdam, Netherlands: Sense Publishers, pp. 57-70. DOI: 10.1007/978-94-6209-974-6_5.

Pedersen, D. B. and Hendricks, V. F. (2013). 'Science Bubbles'. Philosophy E Technology 27 (4), pp. 503-518. DOI: 10.1007/s13347-013-0142-7. 
Petitmengin, C. (2006). 'Describing one's subjective experience in the second person: An interview method for the science of consciousness'. Phenomenology and the Cognitive Sciences 5 (3), pp. 229-269. DOI: 10.1007/s11097-006-9022-2.

Petitmengin, C. and Bitbol, M. (2009). 'Listening from Within'. Journal of Consciousness Studies 16 (10-12), pp. 363-404.

Pickard, K. T. (2012). 'The Impact of Open Access and Social Media on Scientific Research'. Journal of Participatory Medicine 4.

Pickering, A. (1995). The mangle of practice. Chicago, U.S.A.: University of Chicago Press.

Price, D. d. (1963). Little Science, Big Science. New York, U.S.A.: Columbia University Press.

Redfield, R. (1st February 2012). 'Open peer review of our arseniclife submission please'. RRResearch - the Redfield Lab, University of British Columbia.

URL: http://rrresearch.fieldofscience.com/2012/02/open-peer-review-o f-our-arseniclife.html (visited on 19th April 2014).

Rienhoff, H. Y., Yeo, C.-Y., Morissette, R., Khrebtukova, I., Melnick, J., Luo, S., Leng, N., Kim, Y.-J., Schroth, G., Westwick, J., Vogel, H., McDonnell, N., Hall, J. G. and Whitman, M. (2013). 'A mutation in TGFB3 associated with a syndrome of low muscle mass, growth retardation, distal arthrogryposis and clinical features overlapping with Marfan and Loeys-Dietz syndrome'. American Journal of Medical Genetics. Part A 161A (8), pp. 2040-2046.

DOI: 10.1002/ajmg.a.36056. PMID: 23824657.

Roschelle, J. (1998). 'Choosing and Using Vidoe Equipment for Data Collection'. In: Handbook of Research Design in Mathematics and Science Education. Ed. by

A. Kelly and R. Lesh. London, U.K.: Lawrence Erlbaum Associates, Publishers.

Roschelle, J. and Teasley, S. D. (1995). 'The Construction of Shared Knowledge in Collaborative Problem Solving'. In: Computer Supported Collaborative Learning. Ed. by C. O'Malley. Springer Berlin Heidelberg, pp. 69-97.

DOI: $10.1007 / 978-3-642-85098-1 \_5$.

Satne, G. (2015). 'Introduction: from Interacting Agents to Engaging Persons'. Journal of Consciousness Studies 22 (1-2), pp. 9-23. URL: http: //www . ingentaconn ect. com/contentone/imp/jcs/2015/00000022/F0020001/art00001.

Schilbach, L., Timmermans, B., Reddy, V., Costall, A., Bente, G., Schlicht, T. and Vogeley, K. (2013). 'Toward a second-person neuroscience'. The Behavioral and Brain Sciences 36 (4), pp. 393-414. DOI: 10.1017/S0140525X12000660. PMID: 23883742.

Shashok, K. (2010). 'Who's a peer? Improving peer review by including additional sources of expertise'. Journal of Participatory Medicine 2, e15.

URL: http://www . jopm. org/opinion/commentary/2010/12/08/1278/.

Sherin, M. G. and van Es, E. A. (2005). 'Using video to support teachers' ability to interpret classroom interactions'. Journal of Technology and Teacher Education 13 (3), pp. 475-491.

Smith, R. (2010). 'Classical peer review: an empty gun'. Breast Cancer Research 12 (4), S13, pp. 1-4. DOI: $10.1186 /$ bcr2742.

Suleski, J. and Ibaraki, M. (2010). 'Scientists are talking, but mostly to each other: a quantitative analysis of research represented in mass media'. Public Understanding of Science 19 (1), pp. 115-205. DOI: 10.1177/0963662508096776.

Thagard, P. (2012). The Cognitive Science of Science: Explanation, Discovery, and Conceptual Change. Cambridge, MA, U.S.A.: MIT Press.

Thomas, D. and Brown, J. S. (2011). A new culture of learning: Cultivating the imagination for a world of constant change. Lexington, KY, U.S.A.: CreateSpace. 
Thompson, E., ed. (2001). Between Ourselves: Second Person Issues in the Study of Consciousness. Imprint Academic.

URL: http://www.imprint.co.uk/books/between_ourselves.html.

van Noorden, R. (2011). 'Science publishing: The trouble with retractions'. Nature News 478 (7367), pp. 26-28. DOI: 10.1038/478026a.

Varela, F. J. (1996). 'Neurophenomenology: a Methodological Remedy for the Hard Problem'. Journal of Consciousness Studies 3 (4), pp. 330-49.

Varela, F. J. and Shear, J. (1999). 'First-person Methodologies: What, Why, How?' Journal of Consciousness Studies 6 (2-3), pp. 1-14.

Watson, M. (2015). 'When will 'open science' become simply 'science'?' Genome Biology 16, p. 101. DOI: 10.1186/s13059-015-0669-2.

WHO (The World Health Organization) (2011). World Report on Disability. World Health Organization Press.

Wiggins, A. and Crowston, K. (2011). 'From Conservation to Crowdsourcing: a Typology of Citizen Science'. In: Proceedings of the $44^{\text {th }}$ Hawaii International Conference on System Sciences (HICSS-44). Kauai, HI, U.S.A. Pp. 1-10. DOI: 10.1109/HICSS .2011.207.

Young, N. S., Ioannidis, J. P. A. and Al-Ubaydli, O. (2008). ‘Why Current Publication Practices May Distort Science'. PLOS Med 5 (10), e201. DOI: $10.1371 /$ journal.pmed.0050201.

Kristian Moltke Martiny, Ph.D., is head of Psychological and Social Research at the Elsass Institute and a Postdoc researcher at the Center for Subjectivity Research, Department of Media, Cognition and Communication, University of Copenhagen, Denmark. E-mail: kmartiny@hum.ku.dk.

David Budtz Pedersen, Ph.D., is Associate Professor and Research Director at Humanomics Research Centre, Department of Communication \& Psychology, Aalborg University, Denmark. E-mail: davidp@hum.aau.dk.

Alfred Birkegaard, Ph.D., is external lecturer at Department of Philosophy, Roskilde University, Denmark. E-mail: alfredbirkegaard@gmail.com.

\section{How to cite}

Martiny, K. M., Pedersen, D. B. and Birkegaard, A. (2016). 'Open Media Science'. JCOM 15 (06), A02. 